\title{
A percepção de universitários sobre a atuação do intérprete de libras no ensino superior
}

\author{
Jessica Roberta da Silva Corrêa* \\ Ricardo Ernani Sander** \\ Sandra Eli Sartoreto de Oliveira Martins ${ }^{* * *}$
}

\section{Resumo}

O trabalho tem por objetivo analisar a percepção de estudantes surdos e ouvintes sobre a atuação do intérprete de Libras, no contexto universitário. A sua presença e atuação profissional, nessa etapa de ensino, têm sido consideradas um fato recente que, dentre outros aspectos, busca amenizar os obstáculos de comunicação e aprendizagem encontradas por estudantes surdos em processo de formação universitária. Participaram do estudo nove acadêmicos do curso de Arquivologia, sendo um deles surdo, de uma Universidade Pública, localizada no interior do Estado de São Paulo. Os dados foram coletados por intermédio de entrevistas focais, cujas seções de coleta foram registradas por vídeos gravaçóes e, posteriormente, analisadas a partir da técnica de "associação de ideias". Os universitários foram capazes de reconhecer a importância da presença desse profissional, na formação acadêmica do graduando surdo, reforçando a necessidade de medidas institucionais que apoiem a oferta, sem restrição, para efetivação da sua contratação no contexto universitário.

Palavras-chave: Educação superior inclusiva; Intérprete de língua de sinais; Libras.

\footnotetext{
* Graduação em Pedagogia pela Universidade Estadual Paulista Júlio de Mesquita Filho, Marília, São Paulo, Brasil.

** Doutorando em Educaçâo pela Universidade Estadual Paulista Júlio de Mesquita Filho, Marília, São Paulo, Brasil.

*** Professora doutora da Universidade Estadual Paulista Júlio de Mesquita Filho, Marília, São Paulo, Brasil.
} 


\section{The perception of university students on the performance of the interpreter of libras in higher education}

\section{Abstract}

This study aims to analyze the perception of deaf and hearing students about the acting of the interpreter of Brazilian Sign Language - Libras, in the university context. His/her presence and professional activities in this educational stage has been considered a recent fact, that among other things strives to smooth communication and learning obstacles encountered by deaf students in university education process. The participants of this study were nine undergraduate students of Archival Science course, and one deaf academic all from one public university, located in the country side of the state of São Paulo. The data were collected through focus interviews, recorded by video and, later analyzed through the technique of 'idea's association'. The university students were able to recognize the importance of the presence of this professional in the academic formation for the deaf graduate, reinforcing the need for institutional measures that support the offer, without restriction, for the effective execution of its hiring in the university context.

Keywords: University inclusive education; Sign language interpreter; Libras.

\section{Introdução}

Sabe-se que o ingresso na educaçáo superior tem constituído um dos maiores desafios para estudantes que concluíram o Ensino Médio, no contexto brasileiro, dentre os quais se destacam as pessoas com surdez. No entanto, inúmeras são as barreiras que impedem e dificultam a sua formação, no ambiente universitário, das quais se enfatizam as comunicacionais, por serem usuários da Língua Brasileira de Sinais.

As Línguas de Sinais são basicamente diferentes das línguas orais, devido a sua modalidade espaço-visual. A comunicação da língua de sinais é realizada pelas mãos, expressão facial e corporal. Por esse motivo, segundo Pereira (2008, p. 8), o estudante surdo precisa "[...] conviver com outros colegas na mesma condição que tenham fluência nessa língua", nos diferentes espaços, de modo que, na educação, não é diferente. Assim, a falta de informação e de conhecimento acerca da condição da surdez e a forma com que os ouvintes se relacionam com os surdos podem dificultar e/ou favorecer a sua formação, no âmbito universitário.

Dessa maneira, estudos referem que a presença do intérprete educacional de língua de sinais assume um papel fundamental, como, por exemplo, descritos nos trabalhos de Mendes (2012) e Lacerda (2006, 2009). Posto isso, discutir e problematizar a percepção de estudantes surdos e ouvintes sobre a atuação desse profissional, em ambiente universitário, constitui a tônica deste estudo. 


\section{Profissão: intérprete de língua de sinais}

A história da constituição do profissional intérprete de língua de sinais iniciouse a partir de trabalhos voluntários, em espaços informais. No passado, não havia cursos de formação específicos na área da interpretação da Libras. Com o passar do tempo, por meio da expansão da comunidade surda e da sua força na sociedade, através de movimentos da comunidade surda e da conquista do direito dos surdos à cidadania, essa profissão começou a ser valorizada.

Começaram, na década de 1990, os primeiros cursos de formaçóes específicas da área. Sete anos mais tarde, a FENEIS ${ }^{1}$ (Federação Nacional de Educação e Integração de Surdos), em parceria com a UFRGS (Universidade Federal do Rio Grande do Sul), consolidou a formação em Letras/Libras (Libras/Língua Portuguesa), de sorte que a profissão tradutor/intérprete de Libras pôde sair da atuação informal para reconhecimento profissional (QUADROS, 2004).

Esse curso, além de contribuir para uma formação dos profissionais que desejavam atuar nessa área, teve uma vasta propagação através da oferta na modalidade de Educação a Distância, possibilitando levar essa formação a diversas regióes e estados do país. Iniciativas como essa surgem apoiadas pelo órgão internacional que representa os intérpretes de línguas de sinais de todo o mundo, fundado em 2005, na cidade de Worcester, África do Sul, o qual incentivava os profissionais dessa área (SANDER, 2016, p.18). A esse respeito, Lacerda (2010) lembra que a Federação Brasileira das Associaçôes dos Profissionais Tradutores e Intérpretes e Guias-Intérpretes da Língua de Sinais (FEBRAPILS) ${ }^{2}$, com representatividade junto à World Association of Sign Language Interpreters (WASLI), foi criada em 2008.

A partir de então, o reconhecimento legal dessa profissão, na área da surdez, passou a ser valorizada em diferentes espaços e serviços públicos. Antes desse período, os profissionais atuavam de forma voluntária e assistencialista, principalmente na área religiosa, prática ainda necessária em vários contextos, por conta da falta de iniciativa e compreensão do poder público, em especial, das instituiçóes de ensino superior, no âmbito do Estado de São Paulo, de implementarem concursos para contratação dessa função, nas universidades.

No Brasil, com vistas a regularizar de maneira provisória a seleção contratual desses profissionais, em campos de trabalho diversificado, o Ministério da Educação, pelo Decreto no 5.626/2005, estabeleceu o exame PROLIBRAS ${ }^{3}$. O referido Decreto menciona o prazo de dez anos para a oferta do exame. Após esse tempo, a qualificação deverá ser obtida por intermédio de cursos de graduação no ensino superior. $\mathrm{O}$ exame certifica professores de Libras e tradutores e intérpretes de Libras.

Cabe ressaltar que a trajetória desse profissional na educação, suas contribuiçóes no desenvolvimento acadêmico dos surdos e o olhar recente de reconhecimento dessa profissão, legitimados pela Lei no $12.319 / 10$, enfatizam, em seu Art. $2^{\circ}$, que se trata de um profissional capaz de demonstrar

[...] competência para realizar interpretação das 2 (duas) línguas de maneira simultânea ou consecutiva e proficiência em tradução e interpretação de Libras e da Língua Portuguesa. (BRASIL, 2010). 
É comum encontrarmos diferentes formas de designação para fazer referência a esse profissional, ora como tradutor, ora como intérprete, ora com ambas as formas juntas. De acordo com Lacerda (2009, p. 14), “[...] traduzir estaria ligado à tarefa de versar de uma língua para outra trabalhando com textos escritos", ou seja, passar de um código escrito para outro. Não haveria a pressão do tempo e se poderia pesquisar em diversas fontes a melhor tradução para a língua-alvo. Já o termo interpretar tem a pressão do tempo e diz respeito à modalidade falada ou sinalizada de uma para outra. Aqui, segundo Lacerda (2009), a questão está ligada às relaçóes interpessoais, trabalhando na simultaneidade, no instante que acontece, na interação face a face.

No contexto educacional inclusivo, a sua atuação abarca atividades de exercício da função, em várias etapas de ensino, podendo atingir um público usuário da Libras, desde a educação infantil até a universidade. Assim, reconhecer a importância da contratação desse profissional na educação superior, pelas universidades, implicará ao surdo compreender a defesa da formação disciplinar em sua própria língua, pela mediação do intérprete educacional, conforme previsto pelo Decreto no 5.626 (BRASIL, 2005), a partir do seguinte perfil de formação:

Art. 19. Nos próximos dez anos, a partir da publicação deste Decreto, caso não haja pessoas com a titulação exigida para exercício da traduçáo e interpretação de Libras - Língua Portuguesa, as instituiçóes federais de ensino devem incluir, em seus quadros, profissionais com o seguinte perfil:

I - profissional ouvinte, de nível superior, com competência e fluência em Libras para realizar a interpretação das duas línguas, de maneira simultânea e consecutiva, e com aprovação em exame de proficiência, promovido pelo Ministério da Educaçáo, para atuação em instituiçôes de ensino médio e de educação superior;

II - profissional ouvinte, de nível médio, com competência e fluência em Libras para realizar a interpretação das duas línguas, de maneira simultânea e consecutiva, e com aprovação em exame de proficiência, promovido pelo Ministério da Educação, para atuação no ensino fundamental;

III - profissional surdo, com competência para realizar a interpretação de línguas de sinais de outros países para a Libras, para atuação em cursos e eventos.

Parágrafo único. As instituições privadas e as públicas dos sistemas de ensino federal, estadual, municipal e do Distrito Federal buscarão implementar as medidas referidas neste artigo como meio de assegurar aos alunos surdos ou com deficiência auditiva o acesso à comunicação, à informação e à educação. (BRASIL, 2005).

Dorziat e Araújo (2012, p. 395) asseveram que admitir a presença do intérprete de Libras, no espaço educacional, significará necessariamente reconhecer que transformaçôes concretas, nas práticas já estabelecidas, ainda estão por vir nas formas de consolidação e designação desse cargo, nas instituiçóes de ensino. Nesses espaços, o intérprete de Libras deverá assumir a intermediação das relaçóes entre surdos e ouvintes, devendo-se, conforme Quadros (2004), estar atento ao nível educacional em que esse profissional está inserido: 
Nos níveis mais iniciais, o intérprete estará diante de crianças. Há uma série de implicaçóes geradas a partir disso. Crianças têm dificuldades em compreender a funçáo do intérprete puramente como uma pessoa mediadora da relaçáo entre o professor e o aluno. A criança surda tende a estabelecer o vínculo com quem lhe dirige o olhar. No caso, o intérprete é aquele que estabelece essa relação. Além disso, o intérprete deve ter afinidade para trabalhar com crianças. Por outro lado, o adolescente e o adulto, lidam melhor com a presença do intérprete. Nos níveis posteriores, o intérprete passa a necessitar de conhecimentos cada vez mais específicos e mais aprofundados para poder realizar a interpretaçôes compatíveis com o grau de exigência dos níveis cada vez mais adiantados da escolarização. (QUADROS, 2004, p. 62).

Especialmente sobre a atuaçáo desse profissional, no âmbito educacional, considera-se importante ainda mencionar que sua atuação não deve se confundir com a do professor (QUADROS, 2004; DORZIAT; ARAÚJO, 2012), pois caberá a ele “[...] direcionar os questionamentos dos alunos ao professor, pois desta forma o intérprete caracteriza o seu papel na intermediação, mesmo quando este papel é alargado", sem assumir a responsabilidade pelo ensino de conteúdos curriculares ao surdo (QUADROS, 2004, p. 63).

Aliadas a essas questóes, a autora (2004) aponta que as saídas constantes do professor, da sala, para o desenvolvimento de atividades que visem a atender às demandas da direçáo e/ou da coordenação da escola, em tarefas administrativas, observadas como rotineiras, no ensino básico, "[...] infringe[m] diretamente o princípio fundamental de comunicação constante no processo educacional;" Tais posturas alargam cada vez mais lacunas, que consequentemente dificultam a aprendizagem do aluno surdo, em padróes semelhantes à do grupo de ouvintes. Ao comungar das mesmas ideias, assegura-se que o intérprete pode contribuir para auxiliar

[...] a participação do estudante surdo no desenvolvimento da aula, através de perguntas e respostas que exijam tempo dos colegas e professores para que a interaçáo se dê; entender que, em qualquer sala de aula, o professor é a figura que tem autoridade absoluta; e ser auxiliado pelo professor, através da revisão e preparação das aulas, com vistas à qualidade da sua atuação durante as mesmas. (DORZIAT; ARAÚJO, 2012, p. 403).

Nos ambientes de ensino, ele precisa desenvolver seu trabalho em parceria com o professor regente da sala, como facilitador da comunicação, sem confundi-la com a de mero tradutor. Dito de outro modo, as funções desse profissional na educação divergem do processo de interpretação literal de informaçôes dadas em outros contextos de atuaçẫo, como se fosse um language translator ${ }^{4} \mathrm{em}$ atividade durante evento científico, para interpretar palestra na área de medicina (SOUZA, 2007, p. $160)$.

No campo da educação, sua função envolve uma complexidade dialógica, contextual e didática, além de competência linguística nos usos das línguas-alvo, os quais tendem a se complexificar, em decorrência da proficiência linguística exigida nos 
níveis estabelecidos. Embora tais esclarecimentos sejam conhecidos na área da surdez, sabe-se que a presença desse profissional, no campo educacional, ainda tem gerado dúvidas e conflitos dos que nele atuam.

Segundo Lacerda (2009) e Lodi e Lacerda (2010), o termo "Intérprete Educacional - IE" tem sido utilizado em vários países, a fim de demarcar a diferença da sua atuação, em ambientes educacionais. Para trabalhar nesse campo, o profissional precisará demonstrar formação especializada em tradução/interpretação, com ênfase na área pedagógica de ensino da Libras. Assim, ele se tornará parte ativa do processo pedagógico, atuando como mediador da língua falada para a língua sinalizada e viceversa, em sala de aula. Como Dorziat e Araújo (2012), Lacerda (2009) alerta para que a sua atuaçáo não seja confundida, pelo surdo e pelos colegas ouvintes, como substitutivo do trabalho do professor, cabendo ao segundo reconhecer aspectos mínimos da língua de sinais, não deixando toda a responsabilidade de comunicação entre os estudantes surdos/ouvintes para o intérprete, conforme apontado anteriormente. Também será necessário que os demais funcionários da instituição tenham acesso a cursos que visem à disseminação da Libras (RIEGER; DUARTE; OLIVEIRA, 2013).

$\mathrm{Na}$ educação básica, a contratação do intérprete educacional é percebida igualmente como um fato novo. Somada a essa constatação, a sua presença enquanto cargo, nas Instituiçóes de Ensino Superior (IES), caminha a passos lentos. A restrição de propostas que almejem esclarecer tais questôes, elaboradas por gestores, docentes e funcionários das universidades, aliada à falta de políticas institucionais que amparem o processo formativo desses profissionais - sob a condição de que o estudante surdo fique à mercê de voluntarismos e da ajuda dos demais colegas de curso -, negam-lhes o direito de cursar a Educação Superior, mantendo-os afastados dessa etapa de ensino.

Posto isso, o estudo procurou investigar a atuação do intérprete educacional de língua de sinais, na Educação Superior, sob a perspectiva de estudantes ouvintes e surdo, em uma Universidade Pública do Estado de São Paulo. Assim, constitui foco do trabalho identificar e analisar os obstáculos da atuação desse profissional, no exercício da atuação, nessa etapa de ensino, conforme o ponto de vista dos acadêmicos investigados.

\section{Um pouco sobre o contexto da pesquisa}

Aceitaram participar deste estudo 17 estudantes, porém, apenas 9 estudantes (uma surda e 8 ouvintes) compareceram para a coleta de dados, agendada anteriormente. Todos estavam matriculados no curso de Arquivologia de uma Universidade Pública localizada no interior do Estado de São Paulo.

A estudante surda, do sexo feminino, com a idade de 27 anos, oriunda de Marília, interior de São Paulo, tem uma perda total da audição, devido à meningite da mãe, na gravidez. É usuária da língua de sinais. Sua trajetória acadêmica em escolas públicas ocorreu sem a presença do profissional IE.

A intérprete de Libras da acadêmica surda, também oriunda de Marília, cursando o quarto ano de Pedagogia, cooperava de forma voluntária na interpretação. 
Para manter o sigilo dos dados pessoais dos participantes, estes foram identificados no estudo com nomes fictícios: Mônica, Maria, Daniela, Marcos, Laura, Tamara, Bruna, Raquel e Márcia, a estudante surda.

A entrevista focal foi realizada com os acadêmicos ouvintes e a acadêmica surda, servindo de instrumento de coleta de dados para o estudo. Foram constituídos dois roteiros com questóes abertas, para nortear a interação com os participantes. No momento da entrevista com os estudantes ouvintes, a aluna surda esteve presente, porém, não se manifestou, aguardando seu horário da entrevista, a qual foi efetivada em língua de sinais. As entrevistas foram filmadas para posterior tratamento do conteúdo, o qual foi transcrito na íntegra para a Língua Portuguesa, respeitando-se as informalidades das falas dos entrevistados, sendo as mesmas analisadas a partir dos constructos teóricos de Spink (2013).

Examinando as entrevistas, podemos perceber variedades de opiniōes dos participantes, no que tange à percepção a respeito da função do tradutor/intérprete de língua de sinais, no ensino superior, conforme se pretende demonstrar no tópico a seguir. Vale lembrar que o profissional intérprete da Libras atuou como voluntário, não apenas durante esta pesquisa, mas ao longo do curso.

\section{Resultados}

Os resultados deste estudo permitiram identificar as percepçóes dos participantes sobre a atuação do intérprete, na educação superior, conforme relatos de Maria, Bruna, Marcos e Laura (2015):

[...] é o mediador, entre todos que estão ouvindo e as pessoas, eles vão adaptar aquilo. (Maria - estudante ouvinte).

[...] ajuda a gente se comunicar com ela, quando se quer falar alguma coisa com ela, ai pedimos: ai Ana ${ }^{5}$, qual o sinal que podemos fazer? Assim ajuda muito a se comunicar. (Bruna - estudante ouvinte).

Realmente, $[. .$.$] nos ensina a falar, que nem a DA7 falou. Porque$ o intérprete de libras é o porta voz da pessoa e isso caracteriza grande importância no [...] papel porque uma vez você também fala por aquela pessoa, [...] fala por todos para a Márcia. (Marcos - ouvinte).

[...] assim como DA7 e RI2 falaram, a intérprete náo traduz apenas as aulas, mas promove a comunicaçáo para todo mundo, tanto favorece a aula, quanto a interação do meio. (Laura - ouvinte).

Pode-se perceber que, de acordo com os participantes, a presença de um intérprete é de extrema relevância para promover a interação dialógica entre surdos e ouvintes - professores e demais colegas. Márcia (2015) descreve que, "[...] sem o apoio do intérprete", dificilmente compreenderia as aulas e sua aprendizagem seria impossível. A presença do intérprete de Libras, no contexto educacional, torna-se indispensável para o desenvolvimento acadêmico do estudante surdo. Seu papel tem sido tanto favorecer a compreensão dos conteúdos ministrados em sala de aula quanto possibilitar sua interação com o professor e com os demais colegas estudantes. 
No entanto, Laura (estudante ouvinte) aponta que uma das dificuldades observadas na atuação do profissional, na universidade, se deve ao fato de os professores não fornecerem materiais antecipadamente, para que pudessem preparar o trabalho de interpretação dos conteúdos acadêmicos, na universidade.

Paralelamente a essa temática, verifica-se que os professores, nos relatos dos entrevistados, demonstram fragilidades ao conduzir o processo de aprendizagem da estudante surda, na medida em que Márcia confirma que "[...] nenhum material ou prova foram adaptados" ao seu processo formativo, na universidade, atribuindo ao tradutor/intérprete toda a responsabilidade pelas relaçôes de aprendizagem em sala de aula, conforme se nota:

Intérprete importante sempre, sem intérprete não entender aula, ficar boiando. Intérprete passar conteúdos, ajudar conversar com os amigos, professores. Ficar sem intérprete difícil. Já passado não ter aula intérprete junto, eu boiar, mas agora faculdade, interprete junto, melhor inteligente eu, entender tudo, comunicaçáo ok. (MÁRCIA, 2015). ${ }^{6}$

Lacerda (2009, p. 35) confirma essa questão, em seus escritos, ao passo que salienta ser "[...] fundamental que o intérprete educacional seja inserido na equipe educacional"; entretanto, lembra que a sua presença e atuação não irão solucionar todos os problemas educacionais, em sala de aula. De modo geral, caberá a ele intermediar a comunicaçáo entre professor e alunos ouvintes com o aluno surdo inserido nos diferentes espaços formativos. Ressalta ainda que, diferentemente da função do professor, assumirá a função de assegurar a comunicação entre os alunos surdos e demais ouvintes da escola onde está inserido (LACERDA, 2009), evitando que se faça confusão sobre os papéis dos profissionais presentes no ambiente de ensino. $\mathrm{O}$ professor continua como líder e responsável pela sua turma - e isso inclui os alunos surdos. $\mathrm{O}$ intérprete de Libras atua na função de favorecer a interação dialógica em sala de aula e contribui para que o planejamento pedagógico se torne acessível e o mais visual e didático possível aos surdos presentes nesses espaços.

A falta de formação e de conhecimentos específicos sobre a surdez e os processos de aprendizagem desse alunado, aliados à ausência de profissionais contratados para mediar os apoios especializados - como no caso da contratação de profissional em questão - dificultam o êxito da estudante e de sua participação, nas atividades acadêmicas. Tal fato pode ser contado no fragmento do enunciado abaixo, quando Maria (estudante - ouvinte) revela as estratégias que utilizou com Márcia (estudante surda), para realizar um trabalho extraclasse, sem a presença do intérprete:

[...] o trabalho de campo não foi difícil. Eu falei: Márcia, você vai escolher uma pessoa e eu vou fazer uma pergunta. [...] na comunicação foi uma coisa muito assim, a pessoa respondia, eu escrevia, aí eu perguntava para a Márcia: o que você acha? Aí perguntava em baixo: concorda? Aí ela ficava meio assim, algumas vezes ela respondia: ah sim, tranquilo, ou fazia o sinal de estar ok. Aí íamos ao próximo. Então foi muito difícil, pois não consegui captar a opinião dela. Ela estava ali, ela estava participando, mas eu náo 
sabia o que ela estava achando, não sabia se ela gostou, não sabia a opiniáo dela, se ela concordava, ou se ela tinha alguma ideia para fazer as perguntas, eu não consegui captar isto, pois foi eu e ela, e minha forma de comunicaçáo com ela é tentar minimizar algo, fazer gestos, quando não, eu escrevia, e escrevia, aí quando ela começava a perguntar algo eu escrevia: não estou entendendo. Hum? Aí entendia, aí quando não conseguia escrever fazendo a mímica, eu escrevia. Mostrava, ó, é isto? Aí ela entendia, aí eu dizia: ok então. Mas realmente é muito difícil. (Maria - estudante ouvinte).

Os momentos de ausência do intérprete de Libras, nas atividades externas e/ ou nas atividades extraclasse, de acordo com os participantes ouvintes, apenas agravavam a impotência da acadêmica surda de se considerar um membro ativo do grupo e, consequentemente, não conseguia realizar suas atividades:

[...] já tivemos uma atividade em que o intérprete não pôde acompanhar e a comunicaçáo com a Márcia ficou muito complicada. [...] a Márcia conversava comigo pelo papel, assim ia falando suas dúvidas e vontades. Se o intérprete tivesse presente, seria outra coisa. (Maria - estudante ouvinte).

[...] não tive a oportunidade de fazer uma atividade dessa com a intérprete junto, que nem o Marcos teve. A única coisa que sei, é que este processo de eu ter que parar para escrever, não aconteceria. [...] a pessoa falaria e a intérprete interpretaria atrás. E na hora que perguntasse: o que achou? A intérprete na hora interpretaria e ela responderia na hora. [...] (Maria - estudante ouvinte).

Pode-se observar, por meio desses depoimentos, que a presença do intérprete de Libras foi fundamental para garantir a sua participação, no processo formativo. A situação deflagrada pela ausência desse profissional, nas atividades curriculares, revela a fragilidade institucional da universidade, para a contratação e a oferta de serviços especializados, como no caso aqui constatado. Tal medida remete ao fato de o público em questáo depender do apoio voluntário de colegas que demonstrem fluência nessa língua e disposição para acompanhá-los, nas atividades acadêmicas. A pouca expectativa da alteração desse quadro parece apenas corroborar para manter o trabalho voluntário à revelia da Lei ${ }^{\circ} 12.319 / 10$, a qual regulamenta essa profissão, no país (BRASIL, 2010).

Ademais, verificam-se momentos em que Márcia (estudante - surda) confessa ser insuficiente a presença do intérprete de Libras, a fim de auxiliá-la em suas atividades formativas, pois se sente-se "[...] perdida em meio a tantas informaçóes." Tais contextos evidenciam que as baixas expectativas da universitária, quanto ao desempenho acadêmico, aliadas à inadequação das práticas de ensino mediadas pelo português (escrito/falado), como fonte única de transmissáo e verificaçáo dos conhecimentos curriculares, contribuem para mantê-la afastada das situaçôes mais concretas de aprendizagem, nessa etapa de ensino.

Os entrevistados Daniela, Laura e Maria (estudantes - ouvintes) externam opinióes acerca do fato mencionado, acrescentando ser necessário haver investimentos na qualificação profissional para assumir essa tarefa, na universidade. 
[...] eu começaria mudando a visão da surdez nas escolas, pois até eu entrar na universidade, não tinha tido nenhum contato com surdo, aprendi a observar a importância do intérprete, quando tive esta experiência de conhecer um surdo. [...] (Daniela - estudante ouvinte).

Realmente [...] muitas crianças não conhecem uma criança surda, pois nunca teve contato com ela ou com a Libras. Se fosse uma matéria como o inglês por exemplo, mesmo que as pessoas náo conheçam, pelo menos saberão usar a língua de sinais. (Laura estudante ouvinte).

Não só na escola, a importância do intérprete é em todos os lugares, deveriam colocar em prática o que existe no papel [...] (Maria - estudante ouvinte).

Nessa perspectiva, o intérprete deve cooperar junto com o professor nos planejamentos das aulas, participando de reuniôes pedagógicas, fazendo as adaptaçôes e flexibilizaçóes curriculares necessárias, para que o universitário surdo participe plenamente das aulas. Caberá a esse profissional intérprete de Libras desenvolver suas funçôes em parceria com o professor, "[...] atuar frente às dificuldades, dúvidas, questionamentos, ou distanciamento do aprendiz", ou seja, o intérprete deve ser como uma âncora para esses estudantes (LACERDA, 2000, p. 71). Entretanto, os autores alertam que somente a presença "[...] não garante que questôes metodológicas sejam consideradas e também não existe garantia de que o espaço sócio- educacional em um sentido mais geral seja adequado, pois este poderá permanecer às margens da vida escolar, usando uma língua restrita à sua relação com o IE." (LACERDA, 2008, p. 17).

Sabe-se que a comunicação é fundamental para o ser humano e, quando nos referimos ao contexto educacional, essa verdade é ratificada pelo relato de Marcos:

\begin{abstract}
Realmente o intérprete ajuda na comunicação. Eu consegui ver, que sem a intérprete ali, a Márcia seria mais uma no nosso grupo, não estaria participando ativamente. Então é um papel importantíssimo, mas para isto, o intérprete que for contratado terá que ganhar muito bem, pois trabalhará dentro da sala e fora dela, talvez na casa de alguém, ou na biblioteca [...] (Marcos- estudante ouvinte).
\end{abstract}

Assim posto, mesmo diante de todas as dificuldades relatadas, no acompanhamento das atividades dos acadêmicos surdos, há que se trabalhar em favor do reconhecimento e valorização dessa profissão, nos espaços universitários.

\title{
Conclusão
}

O estudo demonstrou que a atuação do intérprete de língua de sinais não deve ser compreendida somente como interpretar os conteúdos, mas torná-los compreensíveis ao universitário surdo. Atuar no atendimento às demandas linguísticas, sem se importar com o seu aprendizado, parece ser uma prática equivocada, nessa área. Assim, reconhecer os limites e as possibilidades da atuação do intérprete, na universidade, implicará agir em favor da aprendizagem, da apropriação dos conteúdos 
acadêmicos, de práticas sociais, entre outras demandas evidenciadas pelos participantes deste estudo. Os atos de interpretar e de aprender, nessa atividade, deverão estar indissoluvelmente unidos, pois neles residem inerentemente seu papel formativo.

Na percepção dos participantes, é urgente e necessário haver o reconhecimento desse serviço, na universidade investigada. Negar a oferta desse profissional ao público em questáo parece impedir que usufrua do direito de continuar os estudos, nessa etapa de educação. Portanto, incluir essa prática no rol das contrataçôes previstas nas IES pode ser um caminho promissor para combater os obstáculos que impedem o acesso e a participação do acadêmico surdo na Educação Superior.

\section{Referências}

BRASIL. Decreto no 5.626, de 22 de dezembro de 2005. Brasília: Presidência da República, Casa Civil, Subchefia para Assuntos Jurídicos, 2005. Disponível em: <http://www.planalto.gov.br/ccivil_03/_ato20042006/2005/decreto/d5626.htm>. Acesso em: 10 fev. 2016.

BRASIL. Lei $\mathbf{n}^{\circ}$ 12.319, de $1^{\circ}$ de setembro de 2010. Regulamenta a profissão de Tradutor e Intérprete da Língua Brasileira de Sinais - LIBRAS. Presidência da República. Casa Civil, 2010. Diário da Uniâo. República Federativa do Brasil (DF) 2 de set 2010

DORZIAT, A.; ARAÚJO, J. R. O intérprete de língua de sinais no contexto da educaçáo inclusive: o pronunciado e o executado. Ver. Bras. Educ. Espec. [online], v. 18, n. 3, p. 391-410, 2012. ISSN 1413-6538. Disponível em: <http://dx.doi.org/10.1590/S1413-65382012000300004>. Acesso em: 29 jan. 2016.

LACERDA, C. B. F. de. A prática pedagógica mediada (também) pela língua de sinais: Trabalhando com sujeitos surdos. Cadernos CEDES (Impresso), Campinas - SP, v. 50, p. 70-83, 2000.

LACERDA, C. B. F. O Intérprete de Língua Brasileira de Sinais: investigando aspectos de sua atuação na educação infantil e no ensino fundamental. 2008. Disponível em: <http://www.ppgees.ufscar.br/LACERDA\%202008\%20Interprete\%20de\%20Libras.pdf>. Acesso em: 07 jul. 2017.

LACERDA, C. B. F. Intérprete de libras. Em atuação na educação infantil e no ensino fundamental. Porto Alegre: Mediação/FAPESP, 2009.

LACERDA, C. B. F. Tradutores e Intérpretes de Língua Brasileira de Sinais: formação e atuaçấo nos espaços educacionais inclusivos. Cadernos de Educaçáo. FaE/PPGE/UFPel: Pelotas, v.36, p. 133-153, maio/ago. 2010.

LODI, A. C. B.; LACERDA, C. B. F. (Org.). Tradutores e Intérpretes de Língua Brasileira de Sinais: Formaçáo e atuação nos espaços educacionais Inclusivos. Cadernos de Educaçáo. Pelotas, p. 133-153, maio/ago. 2010. Disponível em: <http://www.ufpel.edu.br/fae/caduc/downloads/n36/06.pdf>. Acesso em: 12 mar. 2016.

MENDES, R. M. R. Afinal: Intérprete de Língua de Sinais, Intérprete Educacional, Professor-Intérprete ou Auxiliar? O trabalho de Intérpretes na lógica inclusive. São Paulo. FENEIS, p. 75-107, 2012. Disponível em: http://www.porsinal.pt/index.php . Acesso em: 07 mar. 2016.

PEREIRA, R. de C. Surdez: aquisição de linguagem e inclusão social. Rio de Janeiro: Revinter, 2008.

QUADROS, R. M. O tradutor e Intérprete de Língua brasileira de Sinais e língua portuguesa. Programa Nacional de Apoio à Educaçáo de Surdos. Brasília: MEC; SEESP, 2004.

RIEGER, C. P. E.; DUARTE, S. M.; OLIVEIRA, V. R. O tradutor e intérprete de Língua brasileira de sinais no ensino fundamental. Paraná. Unioeste, 2013. Disponível em: <http://cac-php.unioeste.br/eventos/serprof/ anais/trabalhos/artigo/artigo/157.pdf $>$. Acesso em: 11 fev. 2015.

SANDER, R. E. Educaçáo bilíngue de filhos ouvintes de pais surdos (CODAs) com o olhar de pais surdos. 2016. 114 f. Dissertaçáo (Mestrado em Educaçáo) - Universidade Estadual de Maringá, Maringá, 2016.

SOUZA, R. M. S. O professor intérprete de língua de sinais em sala de aula: ponto de partida para se repensar a relação ensino, sujeito e linguagem. Educaçáo Temática Digital, Campinas, p. 154-170, 2007.

SPINK, M. J. Linguagem e produçáo de sentidos no cotidiano [online]. Rio de Janeiro: Centro Edelstein de Pesquisas Sociais, 2010. Referências. p. 68-72. ISBN: 978-85-7982-046-5. Disponível em: <http://static.scielo. org/scielobooks/w9q43/pdf/spink-9788579820465.pdf>. Acesso em: 06 jan. 2016. 
STROBEL, K. Perfil: Entrevista com Karin Strobel. Revista Virtual de Cultura Surda e Diversidade. [2008b]. Disponível em: <http://www.editora-arara-azul.com.br/revista/03/perfil.php>. Acesso em: 09 fev. 2016.

\section{Notas}

${ }^{1}$ FENEIS - Federaçấo Nacional de Educação e Integração dos Surdos - é a entidade de representatividade nacional da comunidade surda brasileira.

${ }^{2}$ FEBRAPILS - Federaçâo Brasileira das Associaçôes dos Profissionais Tradutores e Intérpretes e Guias-Intérpretes da Língua de Sinais. Disponível em: www.febrapils.com.br. Acesso em: 12 set. 2016.

${ }^{3}$ PROLIBRAS é o Exame Nacional editado pelo MEC, para certificaçăo de proficiência no ensino e na traduçăo e interpretação da Libras.

${ }^{4}$ Language translators são profissionais que trabalham como tradutores de línguas, sejam idiomas gerais, sejam línguas de sinais, em diferentes campos de atuação, tais como: cinema, televisão, palestras etc. Para o exercício das atividades relacionadas a sua atuaçáo em etapas formais da educaçáo, tem-se preferido o termo Intérprete Educacional - IE.

${ }^{5}$ Ana é um nome fictício, para garantir o sigilo de imagem da intérprete.

${ }^{6}$ Optou-se por respeitar a estrutura formal do relato em Libras da participante surda, no momento da transcriçâo para a língua portuguesa, dos dados coletados na entrevista.

\section{Correspondência}

Sandra Eli Sartoreto de Oliveira Martins - Universidade Estadual Paulista Júlio de Mesquita Filho, Faculdade de Filosofia e Ciências - Campus de Marília, Departamento de Educação Especial. Rua: Hygino Muzzi Filho, n. 737, Câmpus Universitário. CEP: 17525-900. Marilia, São Paulo, Brasil.

E-mail: jsk_inter@hotmail.com - ricsander@gmail.com - sandreli@marilia.unesp.br

Recebido em 13 de setembro de 2016

Aprovado em 20 de junho de 2017 